\title{
Perspectives from the Survey of Honey Bee Colony Losses During 2015-2016 in Argentina
}

\section{Fabrice Requier $\odot$, Georg K. S. Andersson $\odot$, Facundo J. Oddi, Nancy Garcia and Lucas A. Garibaldi}

\section{Summary}

Several countries have carried out surveys of managed honeybee colonies, the results of which suggest high loss rates all over the world. Although Latin America is an important apicultural region, estimates of honeybee colony losses are lacking. This study quantified colony losses in Argentina during the 2015-16 season. Overall, the survey included 28,204 honeybee colonies, of which $15.5 \%$ were recorded as lost. The total winter losses (13.0\%) were higher than summer losses (3.9\%), a result that contrasts with that collected in Uruguay where no seasonality was observed in the 2013-14 losses. Although interesting, such inter-country variability cannot be analysed for Latin America because of the lack of simultaneous and standardized estimates of colony losses. Therefore, we developed a unified questionnaire to simultaneously record colony losses in 10 countries of Latin America in collaboration with 35 researchers. We address the readers of Bee World and ask them to help distribute the questionnaire among potentially interested parties in Latin America.

\section{Introduction}

Over the past decade, representatives of several countries have carried out surveys of managed honey bee colonies (Apis mellifera), the results of which suggest high loss rates all over the world. For example, the Bee Informed Partnership developed a national monitoring program in the United States, which has been carried out annually since 2007 (Kulhanek et al., 2017). The results of this survey showed that beekeepers in the USA have annually lost between a third to a half of their colonies over the last nine years and, for example, an estimate of $45.2 \%$ loss was recorded during 2012-2013 (Steinhauer et al., 2014). In Europe, the COLOSS consortium developed a winter colony loss survey (which included some non-European countries) and their results revealed losses exceeding 25\% in Belgium, Italy, Netherlands, Scotland and Sweden during the winter of 2009-2010 (van der Zee et al., 2012), as well as in Ireland during the winter of 2015-2016 (Brodschneider et al., 2016). The results of the EPILOBEE epidemiological field survey of European colony health and survival confirmed such trends, whereby $31.7 \%$ of the monitored colonies were lost in Belgium during the winter of 2012-2013 (Chauzat, Bougeard, Hendrikx, \& Ribière-Chabert, 2016; Jacques et al., 2017). These estimates have alerted governments in the USA and Europe to the critical situation in apiculture and have encouraged them to unlock funds to support beekeepers. Latin America is another important apicultural location in the world, however, information about honey bee colony losses is lacking in most of these countries (Requier, Garcia, Andersson, Oddi, \& Garibaldi, 2017). Only recently, Antúnez, Invernizzi, Mendoza, vanEngelsdorp, and Zunino (2017) presented estimates of colony losses in Uruguay during 2013-2014 and Giacobino et al. (2016), in the province of Santa Fe (central Argentina) during the winter of 2012-2013. To fill this knowledge gap, in 2016 we carried out a national monitoring program to assess honey bee colony losses in Argentina (Requier, Garcia, Andersson, Oddi, \& Garibaldi, 2016), the first results of which are presented and discussed here.

\section{Methods}

Our survey was developed to record the rate of honey bee colony losses on a national scale in Argentina (Figure 1) during the season of 2015-2016 (i.e., from 1 October 2015 to 1 October 2016). We used the core questions that we considered "essential" from the COLOSS questionnaire to estimate winter colony loss (van der Zee et al., 2013) and took additional questions from the Bee Informed Partnership (BIP) survey (Kulhanek et al., 2017) to also estimate summer and annual losses. We adapted the "BIP/COLOSS" questions so that they were compatible with South American biogeographic conditions, such as adjusting the seasonal phenology, names of diseases and botanical origin of the honey, and prepared a Spanish translation. To maximize the spatial distribution of the survey, we built a network of beekeepers on a national scale by building a coalition among technicians and governmental agencies, beekeeping associations and research institutes, and named it the National Beekeeping Consortium. We used two participatory methods to address members of this consortium. First, the questionnaire was available directly online as a web-based survey, whereby beekeepers were invited to self-report their rates of colony loss. This invitation was spread by email, beekeeping social networks, the press and included in national beekeeping journals (Requier et al., 2016; Requier, Garcia, et al., 2017). Furthermore, to be able to include Argentinean beekeepers without access to Internet and avoid presenting a biased view of the national beekeeping situation, we also provided a printed version of the survey and made it available through "face-to-face" interviews. The face-to-face interviews were carried out by various beekeeping coordinators who were part of the National Beekeeping Consortium. We estimated the total percentage of losses (i.e., the percentage of colonies lost in a specific group and e.g., national, province of Buenos Aires, province of Neuquén) over a fixed period of time (e.g., summer, winter, annual), and the percentage average losses (i.e., the mean percentage of the total colony loss experienced by operations in a defined 

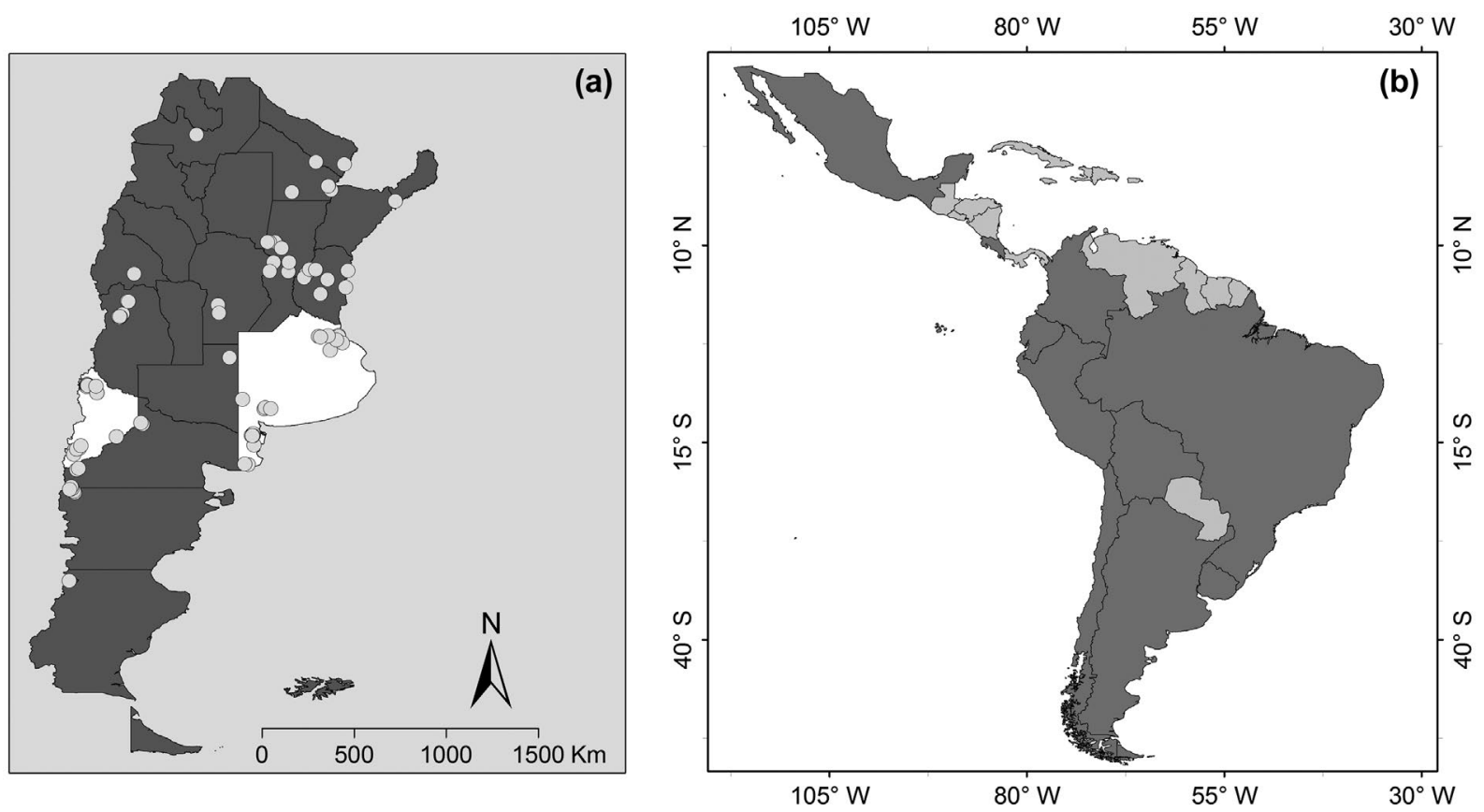

Figure 1. (a) Survey of honey bee colony losses in Argentina during 20 I 5-20 I 6. The location of the zip code of respondents is shown with grey points. Respondents from the same zip code are shown as one point. The two provinces of Neuquén (West) and Buenos Aires (East) are shown in white. These two provinces were selected due to their robust sample size. (b) As a result of the consortium SOLATINA, 35 researchers of the 'colony losses' working group from 10 countries in Latin America (Argentina, Bolivia, Brazil, Chile, Colombia, Costa Rica, Ecuador, Mexico, Peru and Uruguay; in dark grey) have developed a unified questionnaire to estimate the rate of colony losses in these countries during 2016-2017.

group over a defined period of time), using the methods of vanEngelsdorp et al. (2013). Because average loss depends on operation size -a potential factor affecting honey bee colony losses-, we present and discuss the total loss in priority, but both average and total losses are presented in the Figure 2.

\section{Results and discussion}

After a post-validation step was taken to exclude incomplete answers (12 respondents), the responses of the 92 remaining respondents were used to estimate the rate of honey bee colony losses in Argentina during the 2015-2016 season. The responses came from beekeepers who were widely distributed throughout the country (Figure 1(a)) and kept bees in 16 of the 23 Argentine provinces. Provinces without respondents were Jujuy, Catamarca, Tucumán, Santiago del Estero, La Rioja, San Luis and Tierra de Fuego. Nevertheless, less than $6 \%$ of the national livestock of honey bee colonies are found in these provinces (RENAPA, 2017).

The relatively low number of respondents attained confirmed the difficulties inherent in gathering a large amount of data through citizen science programs in South America compared to, for example, Europe and the USA (Silvertown, 2009). Indeed, the participation of Argentinean beekeepers is one-third of that reported for the first season of colony loss surveys in Europe (e.g., 374 respondents from Austria during 2007-2008; Brodschneider, Moosbeckhofer, \& Crailsheim, 2010) and North America (e.g., 334 respondents from the USA during 2007-2008; vanEngelsdorp, Hayes, Underwood, \& Pettis, 2008; and 392 from Canada during 2009-2010; van der Zee et al., 2012). Nevertheless, this level of Argentinean participation is comparable to that reported for other surveys performed in developing countries such as China (127 respondents during 2009-2010, van der Zee et al., 2012), Republic of South Africa (47 respondents during 2009-2010; Pirk, Human, Crewe, \& vanEngelsdorp, 2014) and Uruguay (78 respondents during 2013-2014, Antúnez et al., 2017).

Overall, our sample size comprised 28,204 honey bee colonies, representing from 1 to $2.7 \%$ of the beehive livestock in Argentina. The difference in proportions depends on the origin of the estimate, i.e., from the Food and Agriculture Organization of the United Nations (data for 2013, which is the last year available; FAOSTAT, 2016) or from the recent National Registry of Beekeeping Producers in Argentina (data for 2016; RENAPA, 2017), respectively. The response rate represented about 23.3\% of the beekeepers in Argentina according to the National Registry of Beekeeping Producers (RENAPA, 2017), but this proportion is clearly overestimated because not all the Argentinean beekeepers have yet been registered. Recent studies have suggested that at least $1 \%$ of the beekeepers is an accepted measure for proper representativeness (van der Zee et al., 2013; Brodschneider et al., 2016).

A total of 15.5\% (95\% Confidence Interval 14.0-16.9\%) of honey bee colonies were recorded as lost during 2015-2016 season in Argentina. This first estimate of colony losses in Argentina included high loss rates (i.e., $36.7 \%$ of total loss in the province of Chubut, 95\% CI 11.8-61.5\%) that are much higher than the suggestion of "no reports of high losses" that was made by Neumann and Carreck (2010) and Vandame and Palacio (2010). Nevertheless, the national estimate is much lower than the suggestion of a loss rate of about 30-35\% per year that was made by Maggi et al. (2016). The total winter losses appeared to be much higher than the summer losses (Figure 2). This result contrasts with those reported from the USA, where summer losses were reported as similar to winter losses (Kulhanek et al., 2017) for the third consecutive season (2013-2014 to 2015-2016). No seasonality was observed in the Uruguayan colony losses either during 2013-2014 (Antúnez et al., 2017), suggesting inter-country variability in rates and drivers of Latin American losses. However, because 

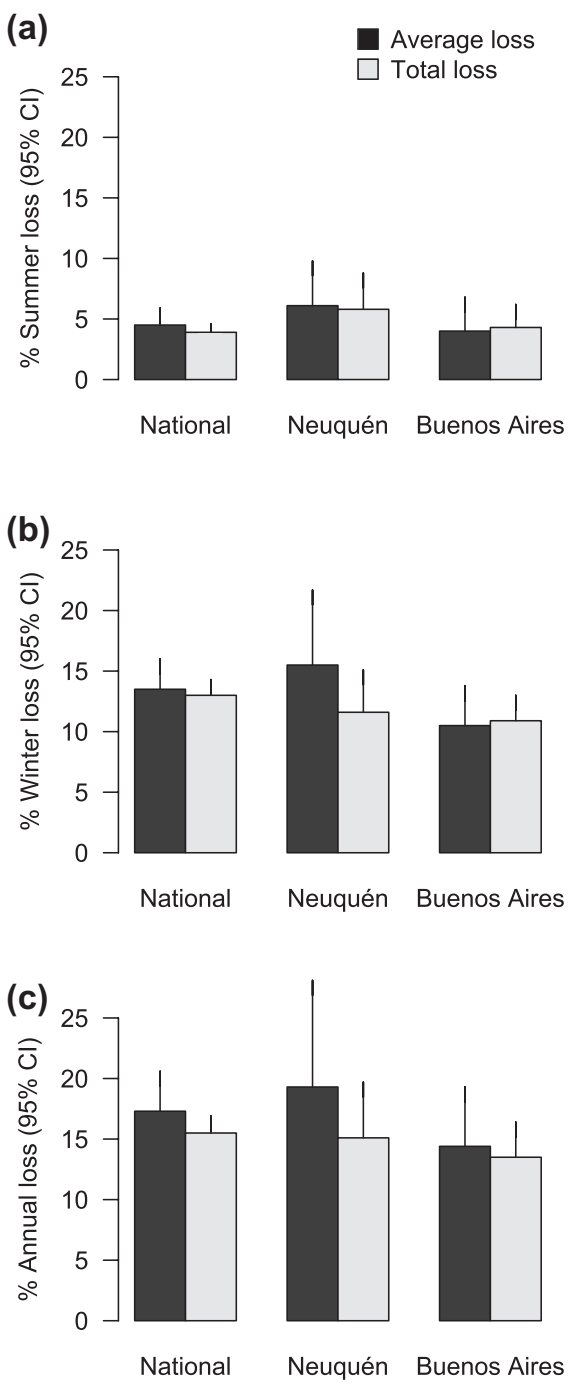

$\Delta$ Figure 2. Colony losses in Argentina during the season of 2015-2016, at national scale and in the two provinces of Neuquén and Buenos Aires. These two provinces were selected due to their robust sample size. More information on the participation rate on other provinces is available in Requier, Garcia et al. (2017). The average loss (in black) and the total loss (in gray) were estimated following vanEngelsdorp et al. (20।3), such as the 95\% Confidence Interval (black lines). (a) Summer losses were registered between I October 2015, and I April 2016; (b) winter losses between I April 20 I6, and I October 20 16; and (c) annual losses between I October 2015, and I October 2016

simultaneous and standardized estimates of colony losses in Latin America are lacking, such conclusions are precipitate. To date, the only study we can conduct is to draw a relative comparison with the results of the USA survey, which used the same monitoring method to assess colony losses over the last nine years. With 28.5\% (95\% CI 22.4-34.5\%) of annual losses recorded in Uruguay during the 2013-2014 season (Antúnez et al., 2017), the relative loss rate is 0.63 compared to the USA (with 45.2 , 95\% CI: $44.58-45.75 \%$ for the same season; Steinhauer et al., 2014). This means that 6.3 colonies were lost in Uruguay for every 10 lost in the USA. The relative loss rate of 0.38 between Argentinean and the USA calculated for the 2015-2016 season (with $40.5 \%$ of total losses, $95 \%$ CI 39.8-41.1\% for the USA; Kulhanek et al., 2017) suggests that both Argentina and Uruguay suffered lower loss rates than the USA for these respective years. The difference in methodologies employed between Uruguay and Argentina and the fact that differences in loss rates between countries can result from yearly differences in climatic conditions (which are not necessarily coupled with climatic conditions in the USA) prevents us from making a direct comparison between Uruguayan and Argentinean loss rates.

Winter colony loss is the most common estimate that has been recorded in many countries and for many years using different survey methods such as BIP (Kulhanek et al., 2017; vanEngelsdorp et al., 2008), COLOSS (Brodschneider et al., 2016; van der Zee et al., 2013) and EPILOBEE (Chauzat et al., 2016; Jacques et al., 2017). The winter loss rate in Argentina (i.e., $13.0 \%$ total loss, $95 \%$ CI 11.7-14.3\%; Figure 2) was placed between European and USA estimates for the same 2015-2016 season, and was reported respectively as $12.0 \%$ (95\% CI $11.8-12.2 \%$; Brodschneider et al., 2016) and 26.9\% (95\% CI 26.4-27.4\%; Kulhanek et al., 2017). In comparison with the estimate of colony losses done by Giacobino et al. (2016) for the winter of 2012-2013 in the province of Santa Fe (i.e. $11.4 \%$ average loss, 95\% CI 8.8-14.1\%), our 2015-2016 estimate is higher for the same province (19.0, 95\% CI 3.1-34.9\%).

The number of colonies per beekeeper differed greatly between respondents from the two Argentinean provinces of Buenos Aires and Neuquén (Figure $1 ; p=0.02$ ), with an average of 512.4 colonies per beekeeper in Buenos Aires (range from 2 to 3,000 colonies) vs. 100.9 in Neuquén (range from 6 to 280 colonies). The two provinces of Buenos Aires and Neuquén were selected due to their robust sample sizes, which were 20 and 24 respondents, respectively (see Requier, Garcia, et al., 2017 for participation rate in other provinces). These sample sizes comprise 9,735 colonies for the province of Buenos Aires and 2,496 colonies for the province of Neuquén. The observed difference in total winter losses between these two provinces (i.e., 10.9, 95\% CI 8.8-13.0\% for Neuquén and 11.6, 95\% CI 8.0-15.1\% for Buenos Aires; Figure 2) suggests that regional effect might matter. Moreover, the observed difference amplification in average winter losses compared to total winter losses (i.e., average winter loss of 15.5, 95\% CI 9.3-21.7\% for Neuquén and 10.5, 95\% CI 7.2-13.8\% for Buenos Aires; Figure 2) suggests that a combination of regional and operation size effects might influence Argentinean winter colony loss rates. This trend concurs with those revealed in many studies conducted all over the world, in which operation size has been identified as a well-established factor affecting honey bee colony losses (see, for example, Brodschneider et al., 2016; Kulhanek et al., 2017; Jacques et al., 2017). We plan to report the results of a detailed statistical analyses of risk assessment of Argentinean losses in a separate scientific publication, including the results of a weight comparison analysis between operation size and other variables such environmental and climate risk factors.

Surprisingly, the beekeepers opinion on potential factors driving their colony losses highlighted the lack in flower resource availability as dominant factor (i.e., $53.7 \%$ of occurrence in the answers) followed by health problems $(34.7 \%$ of occurrence). While lack in flower resource availability is now established to affect honey bee colony losses in Europe (Requier, Odoux, Henry, \& Bretagnolle, 2017), this factor was not pinpointed by Maggi et al. (2016) in the last synthesis of honey bee health in South America, instead of a large development in health problems including Varroosis, RNA viruses and Nosemosis for instance. Future research should evaluate the relationship between honey bee colony losses and the lack in flower resource availability, and its interaction with health problems, also in South America.

\section{Conclusions and perspectives}

Inter- and intra-country variability of colony losses may occur in Latin America, however, the lack of simultaneous and standardized estimates of colony losses prevents us from drawing any firm conclusions. The Latin-American Bee Research Association (SOLATINA) was created in 2016, and has the objectives of strengthening the scientific capacities of the researchers and the institutions they represent, as well as contribute to the knowledge, health and conservation of the bees in this region. The 'colony losses' working group of SOLATINA has developed a unified questionnaire of colony 
losses based on BIP (Kulhanek et al., 2017; vanEngelsdorp et al., 2008), COLOSS (Brodschneider et al., 2016; van der Zee et al., 2013) and EPILOBEE (Chauzat et al., 2016; Jacques et al., 2017). This questionnaire was adapted to address aspects of Latin-American climatic conditions and include other types of beekeeping activities, like meliponiculture (i.e., beekeeping with stingless bees). In October 2017, this unified questionnaire was distributed to beekeepers in 10 countries of Latin America (Argentina, Bolivia, Brazil, Chile, Colombia, Costa Rica, Ecuador, México, Peru and Uruguay; Figure 1(b)). We encourage Latin American beekeepers to continue participating in this 2016-2017 survey of bee colony losses, and we also ask the readers of Bee World to help us distribute the questionnaire (see more details in Requier, Antúnez, \& the SOLATINA's colony loss group, 2017) among the colleagues and beekeepers they know in Latin America.

\section{Authors' contributions}

Fabrice Requier wrote the first version of the text; Fabrice Requier and Lucas A. Garibaldi designed the research project; Fabrice Requier and Nancy Garcia collected the data; Fabrice Requier analysed the data; Fabrice Requier, Georg K. S. Andersson, Facundo J. Oddi, Nancy Garcia, Lucas A. Garibaldi contributed significantly to the drafts and gave their final approval for publication.

\section{Acknowledgements}

Special thanks go to all the volunteer beekeepers that participated in the survey. We thank the members of the National Beekeeping Consortium that helped in the spread of the questionnaire and face-to-face interviews, as well as the "colony losses" working group of SOLATINA for the collaboration on the unified questionnaire to the Latin American survey of colony losses for 2016-2017. We also thank the editor Robert Brodschneider and two anonymous referees for constructive comments on the manuscript.

\section{Funding}

This work was supported by grants from the Agencia Nacional de Promoción Científica y Tecnológica (PICT 20 I 6-0305) and the Universidad Nacional de Río Negro (PI 40-B-567 and PDC 40-B-557).

\section{References}

Antúnez, K., Invernizzi, C., Mendoza, Y., vanEngelsdorp, D., \& Zunino, P. (2017). Honey bee colony losses in Uruguay during 2013-2014. Apidologie, 48(3), 364-370. doi:10.1007/ sl 3592-0 | 6-0482-2

Brodschneider, R., Gray, A., van der Zee, R., Adjlane, N., Brusbardis, V., Charrière, J.D., ... Woehl, S. (2016). Preliminary analysis of loss rates of honey bee colonies during winter 2015/16 from the COLOSS survey. Journal of Apicultural Research, 55(5), 375-378. doi: I0.1080/00218839.2016.12 60240

Brodschneider, R., Moosbeckhofer, R., \& Crailsheim, K. (2010). Surveys as a tool to record winter losses of honey bee colonies: A two year case study in Austria and South Tyrol. Journal of Apicultural Research, 49(I), 23-30. doi: 10.3896/ IBRA. I.49. I.04

Chauzat, M.P., Bougeard, S., Hendrikx, P., \& Ribière-Chabert, M. (20।6). Risk indicators affecting honey bee colony survival in Europe: One year of surveillance. Apidologie 47(3), 348-378. doi: I 0. I 007/s | 3592-0 I 6-0440-z

FAOSTAT (2016). Production database from the Food and Agriculture Organization of the United Nations. Retreieved March, 2017 from http://faostat3.fao.org/browse/Q/QC/S

Giacobino, A., Molineri, A., Bulacio Cagnolo, N., Merke, J., Orellano, E., Bertozzi, E., ... Signorini, M. (20।6). Queen replacement:The key to prevent winter colony losses in Argentina. Journal of Apicultural Research, 55(4), 335-341. doi : 10.1080/002 |8839.2016.1238595

Jacques, A., Laurent, M., EPILOBEE Consortium, RibièreChabert, M., Saussac, M., Bougeard, S., ... Chauzat, M.P. (2017). A pan-European epidemiological study reveals honey bee colony survival depends on beekeeper education and disease control. PLoS One, I2(3), e0 I 7259I. doi: | 0.137 |/journal.pone.017259 |

Kulhanek, K., Steinhauer, N., Rennich, K., Caron, D.M., Sagili, R.R., Pettis, J.S., ... vanEngelsdorp, D. (2017). A national survey of managed honey bee 2015-2016 annual colony losses in the USA. Journal of Apicultural Research, 56(4), 328-340. doi: I 0.1080/002 I 8839.2017.1344496

Maggi, M., Antúnez, K., Invernizzi, C., Aldea, P., Vargas, M. Negri, P., ... Eguaras, M. (2016). Honey bee health in South America. Apidologie, 47(6), 835-854. doi: I0. I 007/s I 3592016-0445-7

Neumann, P., \& Carreck, N.L. (20 I0). Honey bee colony losses. Journal of Apicultural Research, 49( I), I-6. doi: 10.3896/ IBRA. I.49.1.01

Pirk, C.W.W., Human, H., Crewe, R.M., \& vanEngelsdorp, D. (20/4). A survey of managed honey bee colony losses in the Republic of South Africa-2009 to 201 I. Journal of Apicultural Research, 53(I), 35-42. doi: 10.3896/ IBRA. I.53.1.03

RENAPA. (2017). Production database from the National Registry of Beekeeping Producers in Argentina. Retrieved October, 2017 from https://datos.agroindustria.gob.ar/ dataset/registro-nacional-de-productores-apicolas

Requier, F., \& Antúnez, K., \& the SOLATINA's colony loss group. (2017). Honey bee colony loss in Latin America, a standardized survey during 2016-17. Retrieved November. 2017 from https://goo.gl/P82HhV

Requier, F., Garcia, G., Andersson, G.K.S., Oddi, F., \& Garibaldi, L.A. (20|6). Honey bee colony losses: What's happening in South America? American Bee Journal, 156(II), 1247-1250.

Requier, F., Garcia, G., Andersson, G.K.S., Oddi, F., \& Garibaldi, L.A. (2017). La pérdida global de colonias de la abeja melífera: Un mundo de encuestas donde las fronteras persisten. Apicultura sin Fronteras, 92, 13-18.
Requier, F., Odoux, J.F., Henry, M., \& Bretagnolle,V. (2017) The carry-over effects of pollen shortage decrease the survival of honey bee colonies in farmlands. Journal of Applied Ecology, 54(4), | | 6 |-| | 70. doi: 10.1 | | |/13652664. 12836

Silvertown, I. (2009). A new dawn for citizen science. Trends in Ecology and Evolution, 24(9), 467-47I. doi: 10.1016/j. tree.2009.03.017

Steinhauer, N.A., Rennich, K.,Wilson, M.E., Caron, D.M. Lengerich, E.J., Pettis, J.S., ... vanEngelsdorp, D. (20|4). A national survey of managed honey bee 20 I2-2013 annual colony losses in the USA: Results from the Bee Informed Partnership. Journal of Apicultural Research, 53(1), 1-18. doi: |0.3896/IBRA.1.53.1.0

Vandame, R., \& Palacio, M.A. (20I0). Preserved honey bee health in Latin America: A fragile equilibrium due to low-intensity agriculture and beekeeping? Apidologie, 4 I (3), 243-255. doi: 10.105 I/apido/2010025

van der Zee, R., Gray, A., Holzmann, C., Pisa, L., Brodschneider, R., Chlebo, R.,... Wilkins, S. (2013). Standard survey methods for estimating colony losses and explanatory risk factors in Apis mellifera. Journal of Apicultural Research, 52(4). doi: I 0.3896/IBRA. I.52.4. I 8

van der Zee, R., Pisa, L., Andonov, S., Brodschneider, R., Charriere, J.D., Chlebo, R., ... Wilkins, S. (20।2). Managed honey bee colony losses in Canada, China, Europe, Israel and Turkey, for the winters of 2008-9 and 2009-10 Journal of Apicultural Research, 5 I (1), I00-1 | 4. doi: 10.3896/ IBRA.1.5I.1.12

vanEngelsdorp, D., Hayes, J., Underwood, R.M., Pettis, J. (2008). A survey of honey bee colony losses in the U.S., fall 2007 to spring 2008. PLoS One, 3, e407I. doi: I0.137।/ journal.pone.000407|

vanEngelsdorp, D., Lenderich, E., Speen, A., Dainat, B. Cresswell, J., Baylis, K., ... Saegerman, C. (20/3). Standard epidemiological methods to understand and improve Apis mellifera health. Journal of Apicultural Research, 52(1), I-16. doi:10.3896/IBRA.1.52.1.08

Fabrice Requier, Georg K. S. Andersson, Facundo J. Oddi, and Lucas A. Garibaldi

Instituto de Investigaciones en Recursos Naturales, Agroecología y Desarrollo Rural (IRNAD), Sede Andina, Universidad Nacional de Río Negro (UNRN) and Consejo Nacional de Investigaciones Científicas y Técnicas (CONICET), Mitre 630, CP 8400, San Carlos de Bariloche, Río Negro, Argentina Email: requierf@gmail.com Fabrice Requier http://orcid.org/0000-0003-1638-3141 Georg K. S. Andersson iD http://orcid.org/0000-0002-9669-6895 Lucas A. Garibaldi

iD http://orcid.org/0000-0003-0725-4049

Nancy Garcia

Centro Pyme Adeneu, Agencia dedesarrollo económico del Neuquén,Neuquén, Argentina 